\title{
Correction to: Neurological and Medical Complications in Brain Tumor Patients
}

\author{
Mossaed Alyahya $^{1}$ (D) $\cdot$ David Schiff $^{1}$
}

Published online: 14 July 2020

(C) Springer Science+Business Media, LLC, part of Springer Nature 2020

\section{Correction to: Current Neurology and Neuroscience Reports (2020)} https://doi.org/10.1007/s11910-020-01054-2

The order of the authors was inadvertently inverted; Dr. Alyahya is the intended first author. It is corrected above.

Publisher's Note Springer Nature remains neutral with regard to jurisdictional claims in published maps and institutional affiliations.

The online version of the original article can be found at https://doi.org/ 10.1007/s11910-020-01054-2

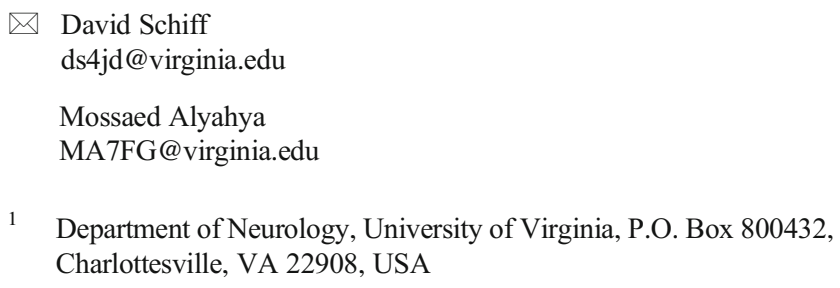

